\title{
Calcification Preceding New Bone Formation Induced by Demineralized Bone Matrix Gelatin*
}

\author{
Kikuji Yamashita and Tomomichi TAKagI \\ Department of Anatomy, University of Tokushima School of Dentistry, Tokushima, Japan \\ Received September 5, 1991
}

\begin{abstract}
Summary. Demineralized bone matrix gelatin (BMG) was implanted into the skeletal muscle of SpragueDawley (S.D.) rats, and histological changes were examined 3, 5, 7, 10 and 15 days later. Before bone formation, a specific calcification process was found in most of the BMG from day 5 and 7 after implantation. The heterotopic calcified sites were not always consistent with the sites of the alkaline phosphatase activity. It was considered that this calcification progresses without any cellular components, and we distinguished this type of calcification as "acellular mineral deposition" from the calcification which occurs in new bone formation. This "acellular mineral deposition" was first observed as small spherical calcified deposits in the BMG on day 7 after implantation; these deposits then gradually grew and fused with each other.

Some multinucleated cells appeared near the site of calcification on day 7 after implantation, but osteoblasts or osteoblast-like cells were scarcely observed around the calcified deposits in BMG until day 7. Vascularization was often observed near the "acellular mineral deposition" and the new bone formation. Fourier transform infrared spectroscopy showed that the calcified deposits in BMG were composed of hydroxyapatite, carbonateapatite and other calcium phosphate components, and that the first two components became prominent with time. It is believed that the "acellular mineral deposition" is due to the deposition of calcium and phosphate into the BMG by a process of heterogenic nucleation that does not involve osteoblasts or matrix vesicles. Bone formation induced by the BMG occurred after the "acellular mineral deposition." The experimental calcification shown in this paper seems a useful model for the study of biocalcification.
\end{abstract}

Intramuscular or subcutaneous implantation of demineralized bone matrix is known to induce new bone formation by endochondral ossification (URIST,
1965). Recently, a bone-inducing factor (BMP: bone morphogenetic protein) in bone matrix has been purified and its cDNA has been obtained (URIST et al., 1984; SAMPATH et al., 1987; WOZNEY et al., 1988). However, the mechanisms of bone induction by BMP, and particularly that of the heterotopic calcification appearing before new bone formation, are unknown yet. LINDEN (1975) reported that this calcification is an important precondition for bone induction, but URIST et al. (1973) did not consider it essential for bone formation. URIST et al. (1977) reported on CIP (Calcification Initiator Protein) extracted from bone matrix, but they did not observe the recalcification of BMG induced by CIP at an early stage; the details of calcification of BMG thus have remained unknown.

We found that the calcification of BMG ("acellular mineral deposition") occurred independently before bone induction but that the calcification had some significance regarding bone formation induced by BMG (YAMASHITA et al., 1991a). In this work, we examined this "acellular mineral deposition" by histological observations, quantitative analyses of calcium and phosphate, electron probe X-ray microanalysis, electron diffraction and Fourier transform infrared spectroscopy. We also attempted to confirm that the "acellular mineral deposition" was necessary for the process of bone induction.

\section{MATERIALS AND METHODS}

\section{Preparation of demineralized bone matrix gelatin}

Demineralized bone matrix gelatin was prepared as described previously (YAMASHITA et al., 1991b). BMG particles of $75-500 \mu \mathrm{m}$ were collected and lyophilized.

\footnotetext{
*This work was supported by a grant from the Ministry of Education, Science and Culture, Japan (02670808).
} 


\section{Implantation}

Sixty-three male rats 5 weeks old were anesthetized by subcutaneous injection of pentobarbital sodium (Abbott Laboratories), and $2.0 \mathrm{mg}$ of BMG was implanted into the right rectus abdominis muscle under sterile conditions.

\section{Histological preparation}

Muscle tissues containing implants were removed from five rats each on days $3,5,7,10$ and 15 after the implantation of BMG. These specimens were frozen in liquid nitrogen. Cryostat sections were cut at a 5 $\mu \mathrm{m}$ thickness, mounted on glass slides and air-dried for $15 \mathrm{~min}$. Sections were stained with hematoxylin and eosin (H-E), von Kossa, alizarin red $\mathrm{S}$ and for alkaline phosphatase (Sigma Kit No. 86-c). In addition, on day 10 after implantation, Indian ink was injected into the left ventricle of two rats and their muscles containing implants were removed, frozen in liquid nitrogen and examined histologically by the procedure described above.

Furthermore two rats each were also killed on days $3,5,7,10$ and 15 after implantation, and afterwards infused through the heart with the saline with 10 units/ml sodium heparin (Novo Industry, Denmark) and then freshly prepared $2.5 \%$ glutaraldehyde in 100 $\mathrm{mM}$ sodium phosphate buffer, $\mathrm{pH}$ 7.4. For the preparation of specimens for light microscopy, the implants with surrounding tissues obtained after perfusion fixation were immersed in ice-cold $2.5 \%$ glutaraldehyde and fixed for $2 \mathrm{~h}$ at $4^{\circ} \mathrm{C}$. They were then washed in three changes of phosphate buffered saline, postfixed in osmium tetroxide in phosphate buffer, $\mathrm{pH}$ 7.4, dehydrated in an ethanol series, and embedded in Epon 812. Sections were double-stained with uranyl acetate and lead citrate, and examined with a Hitachi H-800 transmission electronmicroscope. Semithin sections were stained with toluidine blue, alizarin red S (YAMASHITA et al., 1991c) and basic fuchsin-methylene blue.

\section{Quantitative analysis of calcium and phosphate}

Muscle tissues containing the implants were removed from four rats each on days 3, 5, 7, 10 and 15 after implantation. The tissues were homogenized in $2 \mathrm{ml}$ of ice cold $0.25 \mathrm{M}$ sucrose- $3 \mathrm{mM} \mathrm{NaHCO}$ s solution in a glass-glass homogenizer for three $10 \mathrm{sec}$ bursts at the maximum setting. The homogenates were centrifuged at $12,000 \times \mathrm{g}$ for $15 \mathrm{~min}$ at $2^{\circ} \mathrm{C}$, and the resulting precipitates were ashed in conc $\mathrm{HNO}_{3}, 30 \%$ $\mathrm{H}_{2} \mathrm{O}_{2}$ and $6 \mathrm{M} \mathrm{HClO}_{4}$ on a hot plate. The residues were extracted with $4 \mathrm{ml}$ of $25 \mathrm{mM} \mathrm{HClO}_{4}$ for $48 \mathrm{~h}$, and the extracts were diluted with $6 \mathrm{ml}$ of water for determination of calcium and phosphate by ionexchange chromatography (Dionex 2020i). Calcium and phosphate contents were expressed in $\mu$ mole per implant.

\section{Electron probe X-ray microanalysis}

Specimens with calcified deposits on day 7 after implantation were embedded in Epon 812 as described above. Sections of about $1 \mu \mathrm{m}$ thickness were cut on an LKB ultramicrotome (LKB, Sweden), and mounted on copper grids. Calcified deposits were analyzed with an electron microscope (Hitachi H-500, Tokyo, Japan) fitted with a Kevex energy dispersive $\mathrm{X}$-ray analysis system. All analyses were carried out at $10 \mathrm{KeV}$ for $100 \mathrm{sec}$.

\section{Electron diffraction}

Calcified deposits in sections of about $90-150 \mathrm{~nm}$ thickness on copper grids were analyzed in an electron microscope (Hitachi H-800, Tokyo, Japan ). Rat long bones were analyzed as the control.

\section{Fourier transform infrared spectroscopy}

Muscle tissues containing implants were removed from two rats each on days 7, 10 and 15 after implantation of $\mathrm{BMG}$, and frozen in liquid nitrogen. Cryostat sections were cut at $5 \mu \mathrm{m}$ thickness and mounted on glass slides covered with aluminum. The infrared spectrum in the range of $750-4,000 \mathrm{~cm}^{-1}$ was measured using a Fourier transform infrared spectrometer with microscope (FTS-40, UMA 300A, Bio-Rad Laboratories, Richmond, CA.) . Amorphous calcium hydrogen phosphate and hydroxyapatite were measured in the same way.

\section{RESULTS}

\section{Histological observations}

The density and distribution of calcified sites in the BMG were examined by staining with alizarin red S, and the localization of alkaline phosphatase was also determined. By day 3 , the surrounding muscle fibers had degenerated and many fibroblasts were present in the connective tissue near the BMG. The histological appearances of calcification of BMG on days 5, 7, 10 and 15 after implantation are shown in Figure 1. Alizarin red S stained spherical heterotopic calcified deposits ("acellular mineral deposition") in the periphery of the BMG on day 5 in some specimens or day 7 after implantation; later the stained areas extended centripetally to the center of the BMG (Fig. 1b). New bone formed at the sites that were contigu- 

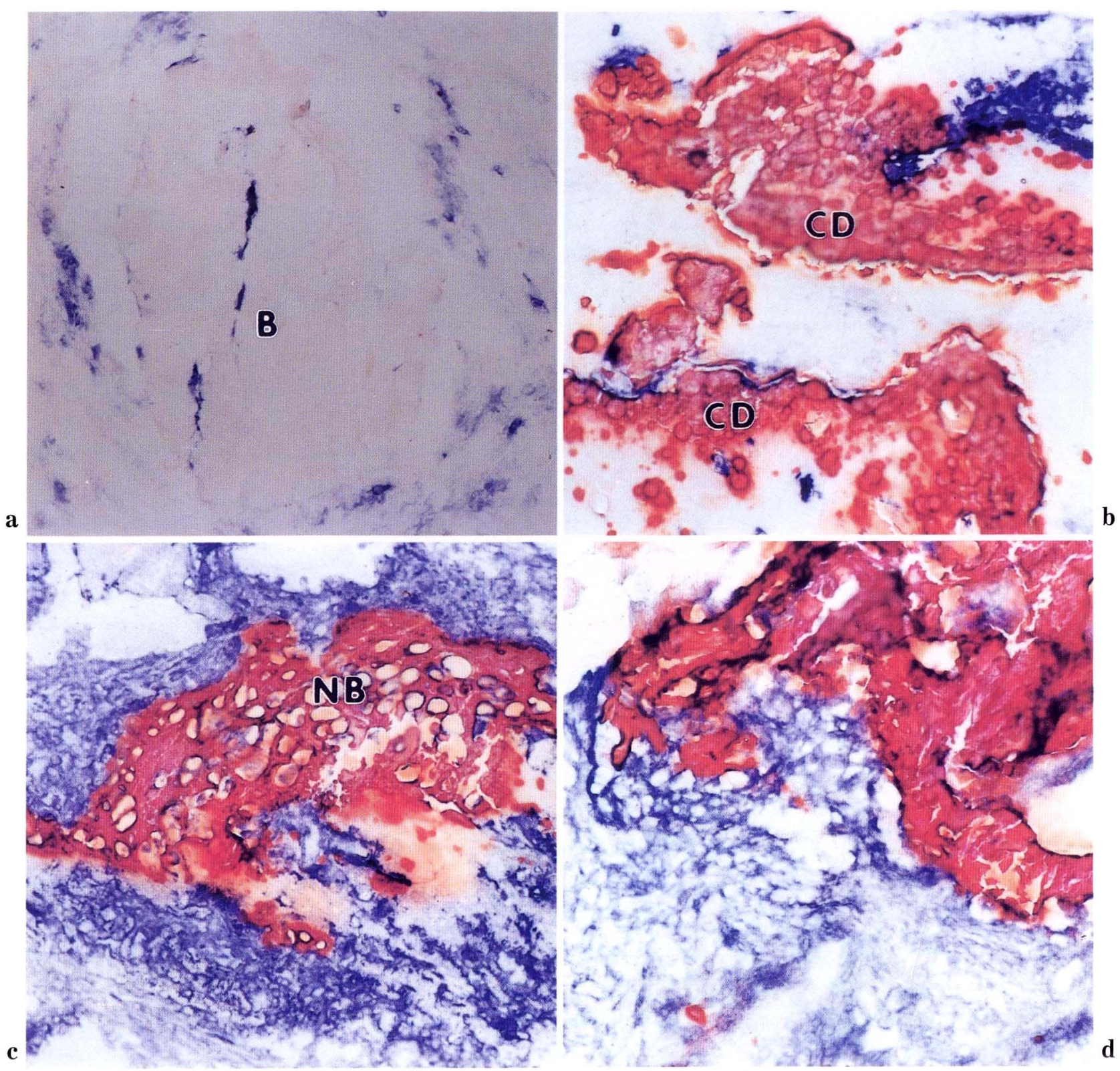

Fig. 1. Calcification of BMG and alkaline phosphatase activity. Tissues were removed on days 5 (a), 7 (b), 10 (c) and 15 (d) after implantation and stained with alizarin red S and for alkaline phosphatase. Calcified deposits $(C D)$ are seen on day 7 after implantation and increase with time. Alkaline phosphatase activity is shown around the BMG $(B)$ on day 5 and increases with time. New bone $(N B)$ possesses lacunae containing osteocytes which coincide with the areas of high alkaline phosphatase activity, but not with the calcified deposits $(C D)$. The greater part of implants undergoes calcification on day 15 . a-d: $\times 125$

ous to the BMG, near the acellular mineral deposits on day 10 , but it was difficult to distinguish the exact border between the regions of "acellular mineral deposition" and bone (Fig. 1c, d). Alkaline phosphatase activity was first detected near the BMG on day 5 and its activity in this region increased from day 7 to 10 . The "acellular mineral deposition" site of BMG differed from the area of high alkaline phosphatase activity on day 7 after implantation (Fig. 1b), but on day 10 after implantation new bone was close to 


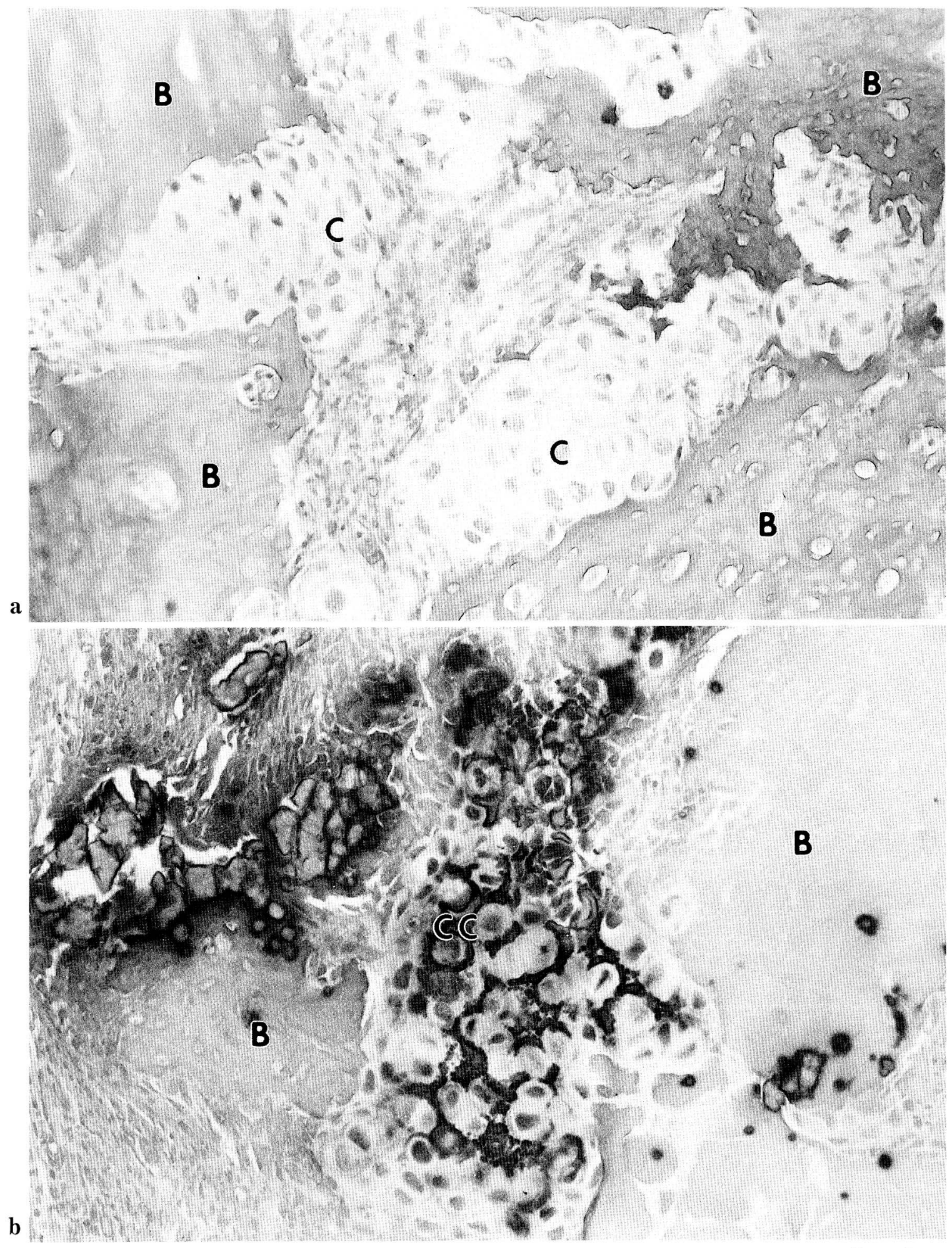

Fig. 2. Cartilage formation on day 7 (a) and on day $10(\mathbf{b})$ after implantation. a. Uncalcified cartilage tissue $(C)$ forms among implanted BMG $(B)$. b. Calcification is shown in cartilage tissue $(C C)$. a, b: Alizarin red S staining, $\times 250$ 


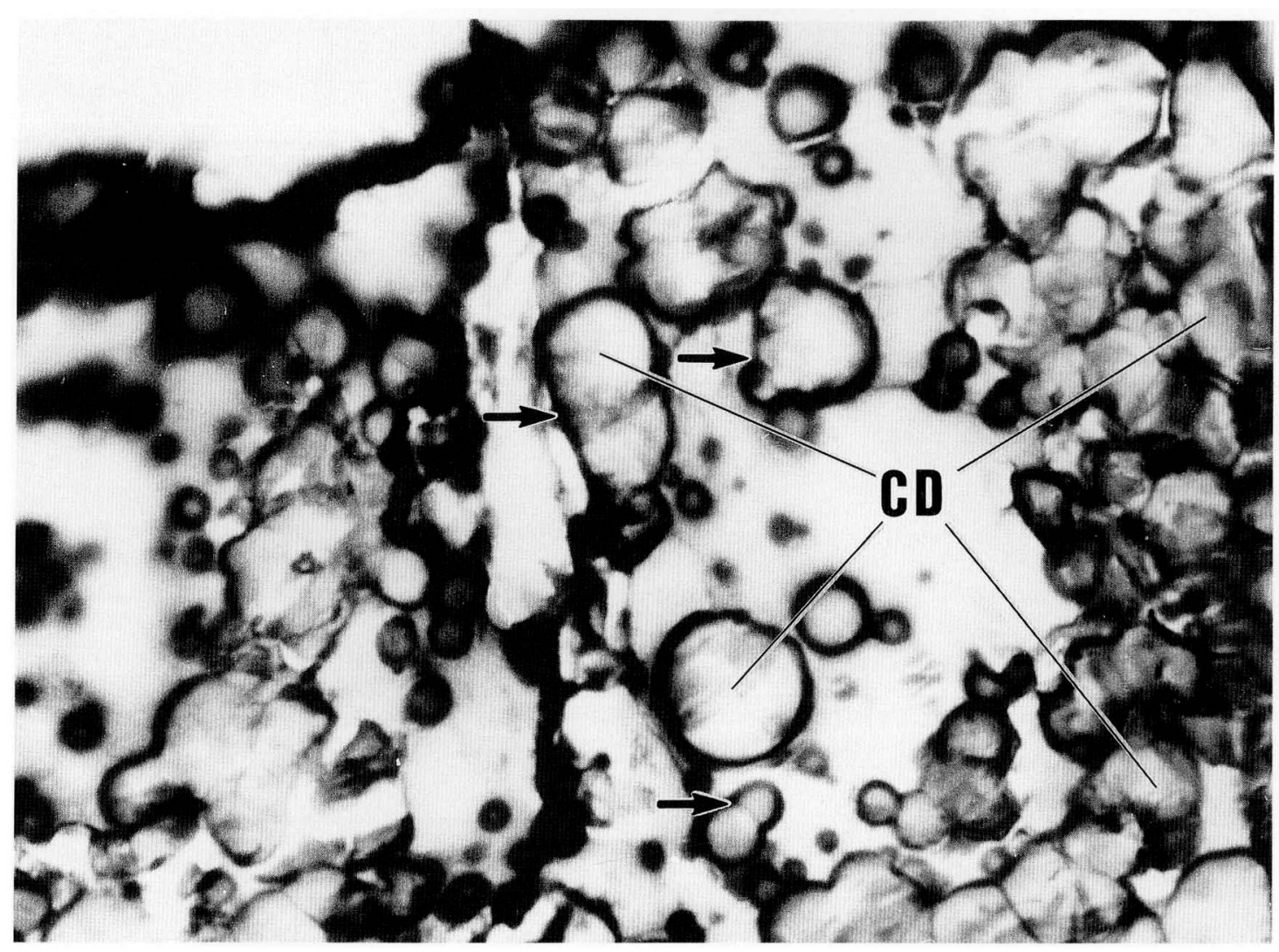

Fig. 3. "Acellular mineral deposition" stained with alizarin red S in the BMG on day 7 after implantation. Many calcified deposits $(C D)$ of $1-18 \mu \mathrm{m}$ diameter are seen. Small deposits are completely calcified, but large ones are calcified only at their periphery. Some calcified deposits are fused together (arrows). $\times 450$

those of alkaline phosphatase activity (Fig. 1c, d). New cartilage formation was seen in some places in or near the BMG, but rarely was calcified cartilage observed on day 7 after implantation (Fig. 2a). Calcified cartilages were seen on day 10 (Fig. 2b).

The spherical calcified deposits observed on day 7 after implantation varied greatly in diameter, from $1 \mu \mathrm{m}$ to $18 \mu \mathrm{m}$ (Fig. 3). Small deposits were stained with alizarin red $\mathrm{S}$, but large deposits were stained strongly at their peripheries, their centers being scarcely stained with alizarin red S (Fig. 3). Some small deposits tended to fuse with one another to form large deposits (Fig. 3). The inner portions of fused deposits contained some debris that was different from the substratum of BMG that was sensitive to toluidine blue (Fig. 4 a). On day 7 , some multinucleated cells which varied greatly in size and number of nuclei and possessed faintly acidophilic cytoplasm, appeared near the "acellular mineral deposition"; osteoblasts or osteoblast-like cells were rarely seen (Fig. 4b ). The fused deposits in semithin sections were stained with alizarin red S (Fig. 4c). On day 15, fused calcified deposits were still observed near the sites of bone formation and many osteoblasts (Fig. 5a). These osteoblast-like cells secreted matrix vesicles, and mineral crystals were accumulated on new collagen fibers (Fig. 5b). On the other hand, fused heterotopic deposits which were enclosed by the well-calcified peripheral area were seen (Fig. 6a) and the spherical "acellular mineral deposits" (Fig. 6b) were completely surrounded by the uncalcified BMG matrix, and no matrix vesicle-like structures were detected. The heterotopic calcified deposits of various shape were apt to fuse with each other (Fig. 7a). Needle shaped crystals were seen in the peripheral area of these deposits (Fig. 7b). 


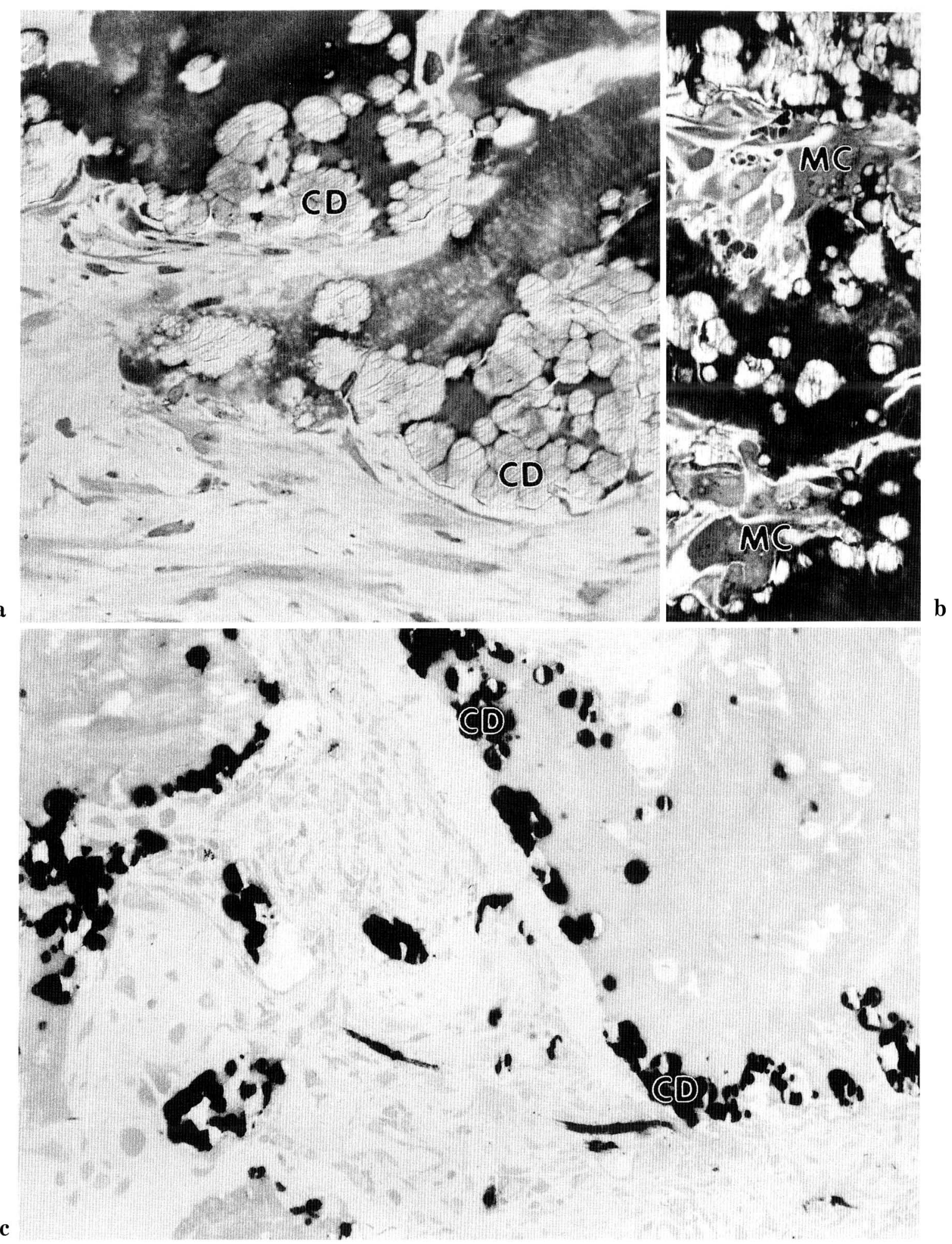

Fig. 4. "Acellular mineral deposition" in BMG on day 7 after implantation. a. Heterotopic calcified deposits $(C D)$. Mononucleated cells are rarely recognized adjacent to BMG. b. Some multinucleated cells $(M C)$ are shown near the calcified BMG. a, b: Semithin Epon sections stained with toluidine blue. $\mathbf{c}$. These deposits $(C D)$ are stained with alizarin red $\mathrm{S}$ in a semithin section. $\times 250$ 


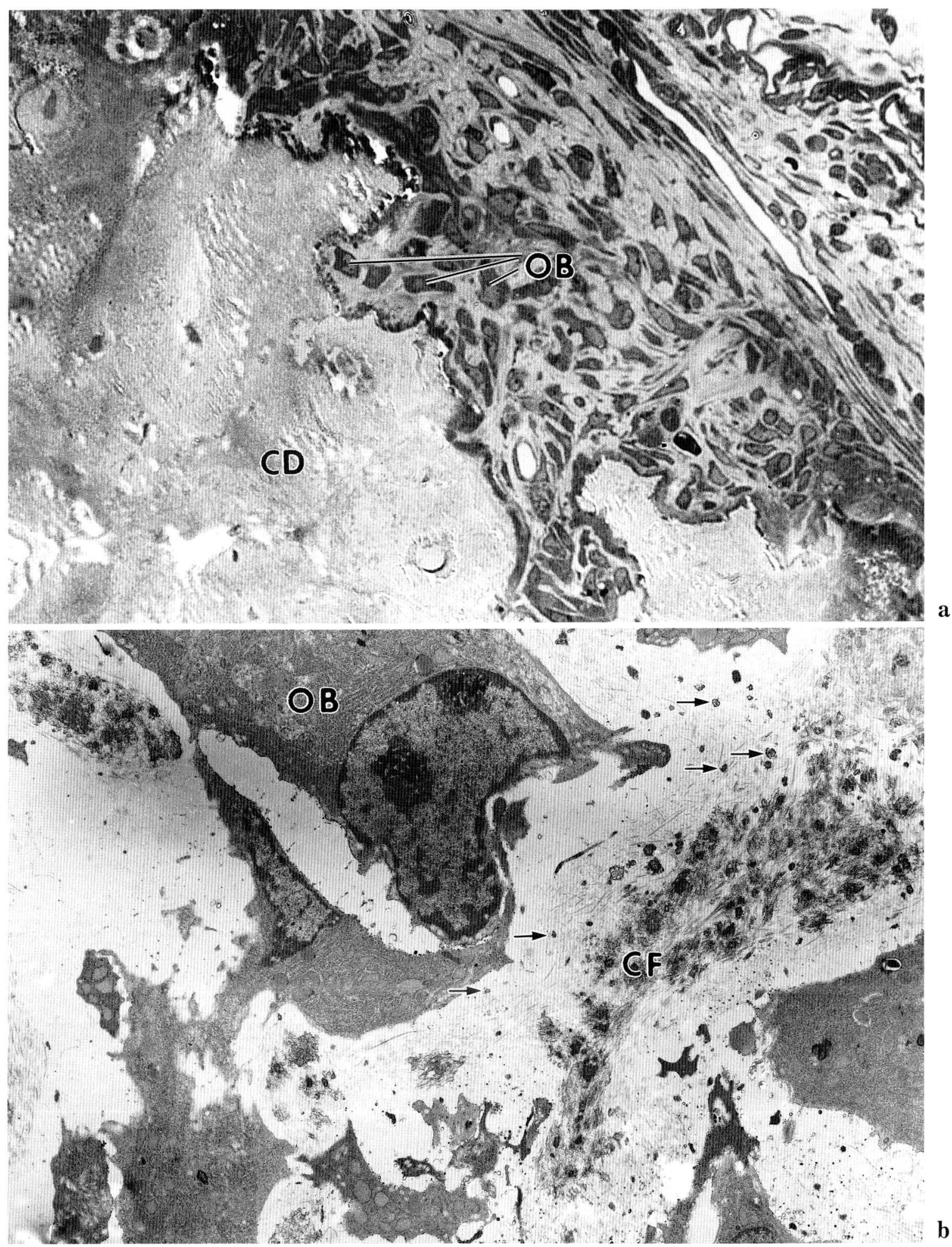

Fig. 5. New bone formation on day 15 after implantation. a. Fused calcified deposits $(C D)$ are still seen. Many osteoblast-like cells $(O B)$ are seen near the sites of "acellular mineral deposition". $\times 250$. b. Electron micrograph. Osteoblast-like cell $(O B)$ secreting matrix vesicle-like structures (arrows) which accumulate on new collagen fibers $(C F) . \times 5,400$ 


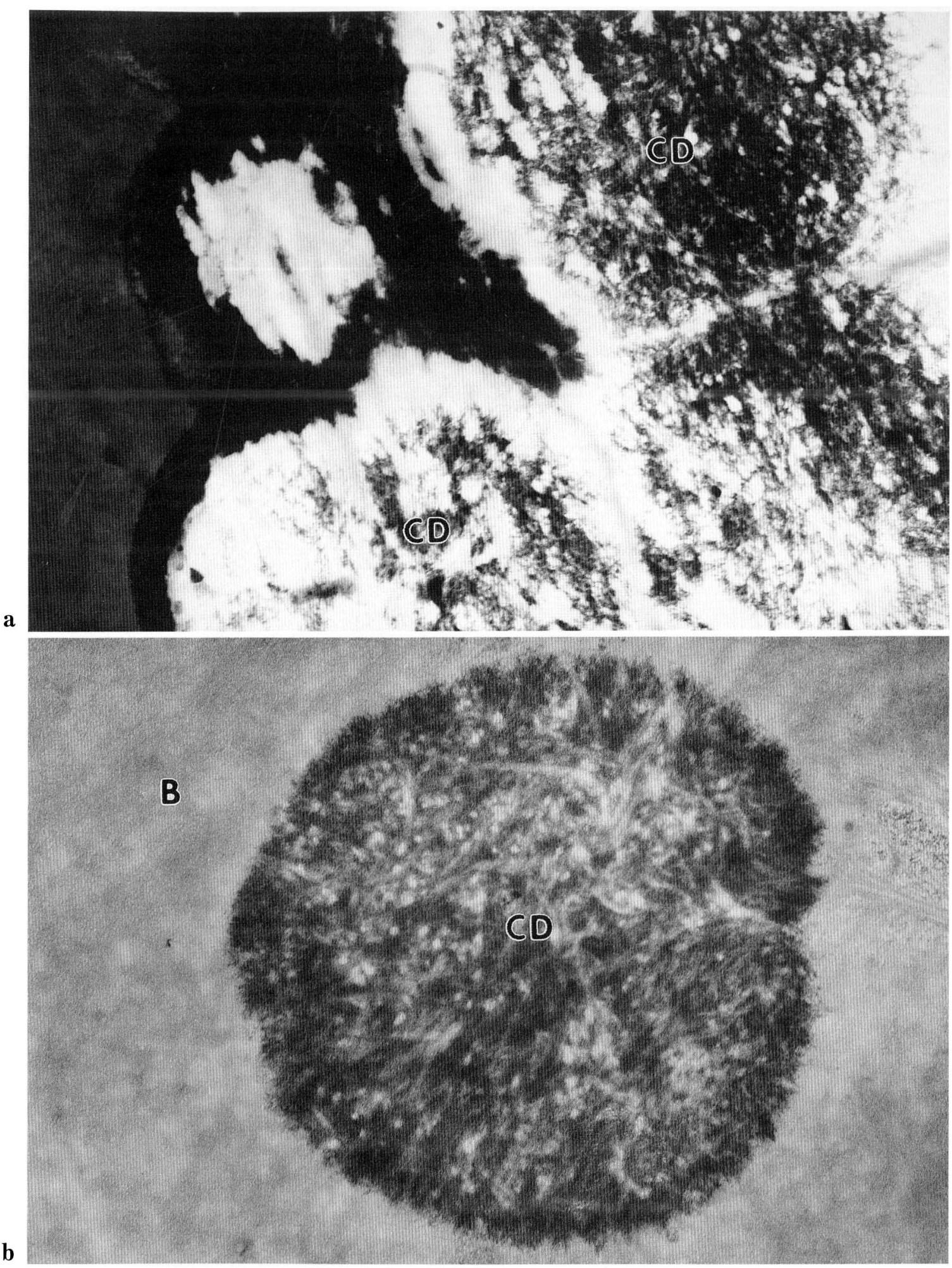

Fig. 6. Electron micrographs of "acellular mineral deposition" on day 7 after implantation. a. Fused calcified deposits $(C D)$ with well calcified peripheral area are seen. $\times 7,200$. b. Spherical heterotopic calcified deposit $(C D)$ is completely surrounded by the uncalcified matrix of BMG $(B) . \times 27,000$ 

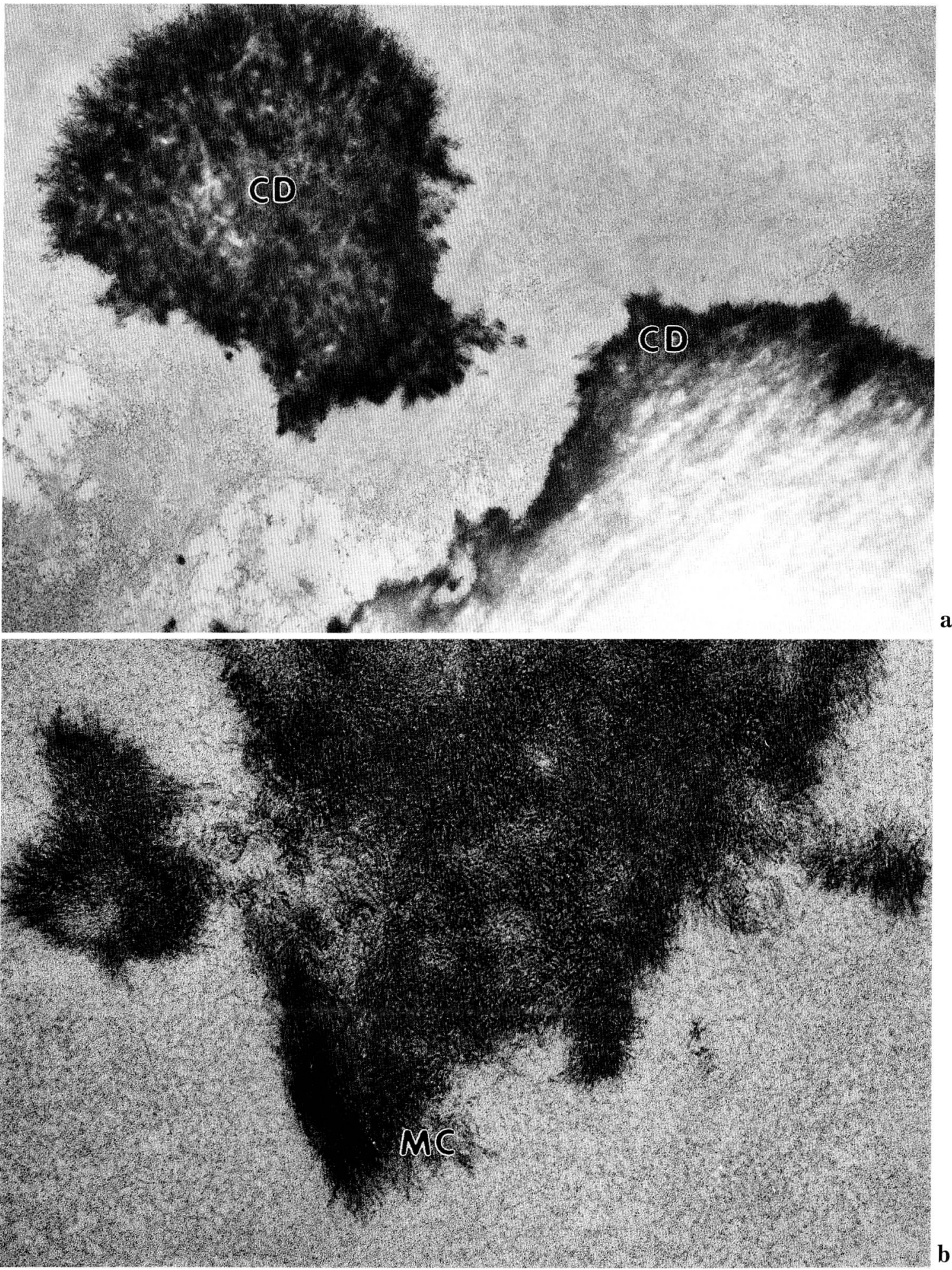

Fig. 7. Electron micrographs of "acellular mineral deposition" on day 7 after implantation. a. Amorphous deposits $(C D)$ are seen to fuse with each other. $\times 27,000$. b. Mineral crystals $(M C)$ are seen in the peripheral area of the deposits. $\times 108,000$ 


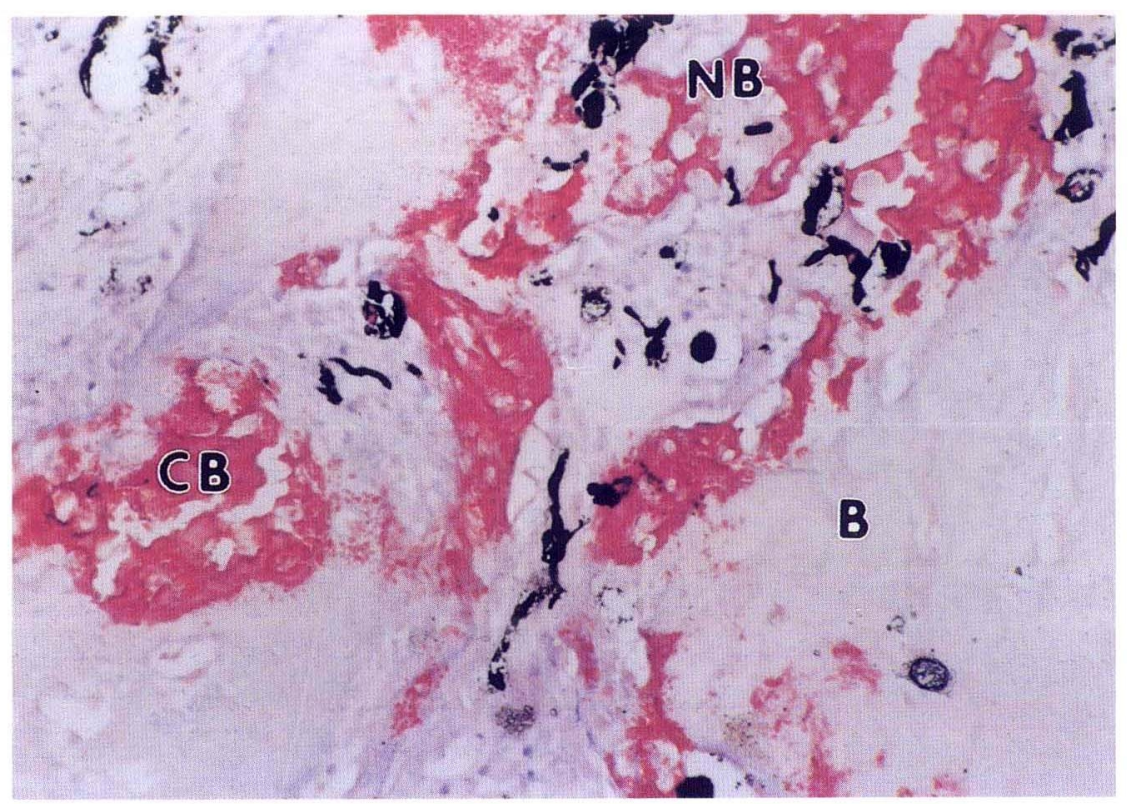

Fig. 8. Newly-formed blood vessels containing injected Indian ink and calcification of the BMG $(C B)$ stained with alizarin red S. Many vessels are seen near the sites of calcification of the BMG, and the new bone $(N B)$ possesses lacunae on day 10 . $B$ uncalcified $B M G$. $\times 125$

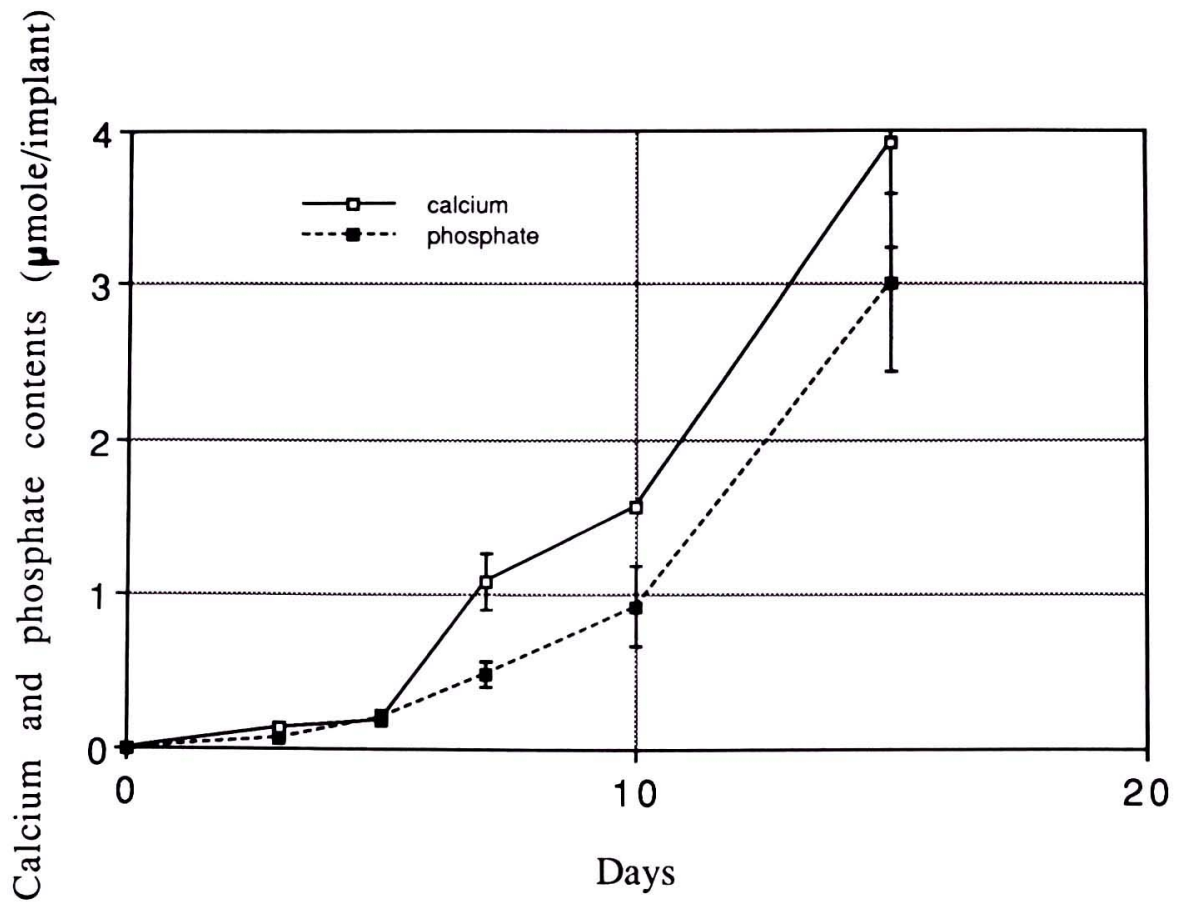

Fig. 9. Changes in calcium and phosphate contents of implants. Values are means \pm SD for four determinations. The contents begin to increase on day 7 and continue to increase until day 15 or later.

The histological appearance of new vascularization around the BMG after the injection of Indian ink is shown in Figure 8. New blood vessels were found around the sites of "acellular mineral deposition" of the BMG and of new bone on day 10 after implantation (Fig. 8). On the other hand, new blood vessels were rarely recognizable near the uncalcified $\mathrm{BMG}$ on day 10.

\section{Calcium and phosphate contents}

Data on changes in the calcium and phosphate contents of implants are shown in Figure 9. The calcium content increased slowly with time to day 5 , then rapidly from day 7 after implantation. The phosphate content also similarly increased. The calcium/phosphate ratio on days 10 and 15 after implantation 
corresponded to the hydroxyapatite ratio (day $3: 1.88$, day $5: 1.34$, day $7: 2.01$, day $10: 1.70$, day $15: 1.69$ ).

\section{Electron probe $\mathrm{X}$-ray microanalysis}

Energy dispersive X-ray microanalysis of areas stained strongly with alizarin red $\mathrm{S}$ showed distinct energy peaks of calcium and phosphorus (Fig. 10). This X-ray energy spectrum suggested that the acellular mineral deposits in the BMG consisted of calcium and phosphorus.

\section{Electron diffraction}

The electron diffraction pattern of regions that stained well with alizarin red $\mathrm{S}$ on day 7 after implantation showed the appearance of an apatite crystal structure (Fig. 11). The pattern was similar to that of rat femora.

\section{Fourier transform infrared spectroscopy (FT-IR)}

FT-IR spectra of regions of "acellular mineral deposition" in the BMG on days 7 and 15 after implantation are shown in Figure 12. The mineral components in the calcified area contained phosphate, carbonate and hydroxy groups. The peaks at 960 and $1,010 \mathrm{~cm}^{-1}$ of phosphate groups, which are characteristic of hydroxyapatite, became prominent on day 15. These results suggested that phosphate groups $\left(870-1,100 \mathrm{~cm}^{-1}\right)$ were present in complexes of hydroxyapatite (964 and $1,010 \mathrm{~cm}^{-1}$ ) and amorphous calcium hydrogen phosphate $\left(981\right.$ and $\left.1,060 \mathrm{~cm}^{-1}\right)$, and that the hydroxyapatite became prominent with time. The two major bands of carbonate at 1,423 and 1,488 $\mathrm{cm}^{-1}$ were seen on day 7 and that at $1,419 \mathrm{~cm}^{-1}$ became prominent by day 15 .

\section{DISCUSSION}

There have been few reports of heterotopic calcification before new bone formation induced by BMG. Regarding bone induction by BMG or BMP, many reports have been related to their cellular components. They have paid attention to the appearance and distribution of cells after implantation. However, we noted the calcification site and the changes of BMG especially just after implantation. The present study by demonstrated calcification in the BMG to occur on all specimens on days 5-7 after implantation in the absence of osteogenic cells. The calcium and phosphate contents of the implants also increased from day 7 .

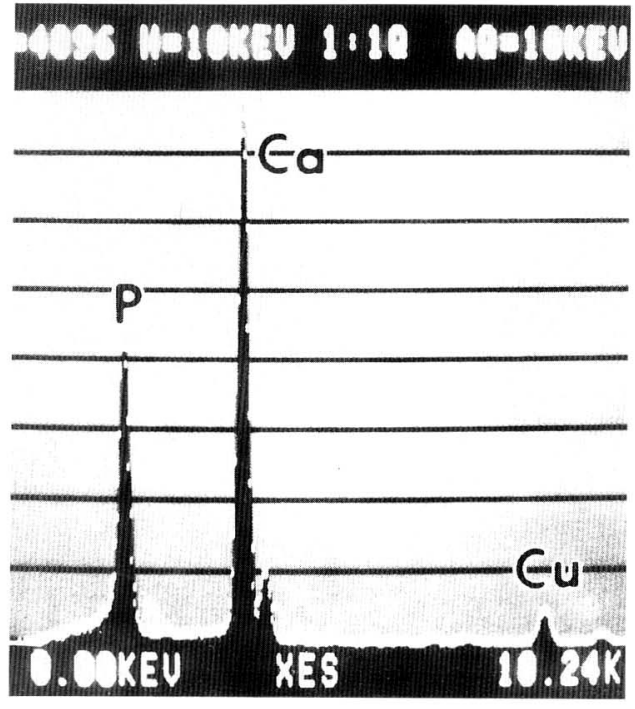

Fig. 10. Energy dispersive X-ray microanalysis spectrum of the calcified deposits in the BMG on day 7 after implantation, demonstrating distinct peaks for $\mathrm{Ca}$ and $\mathrm{P}$.

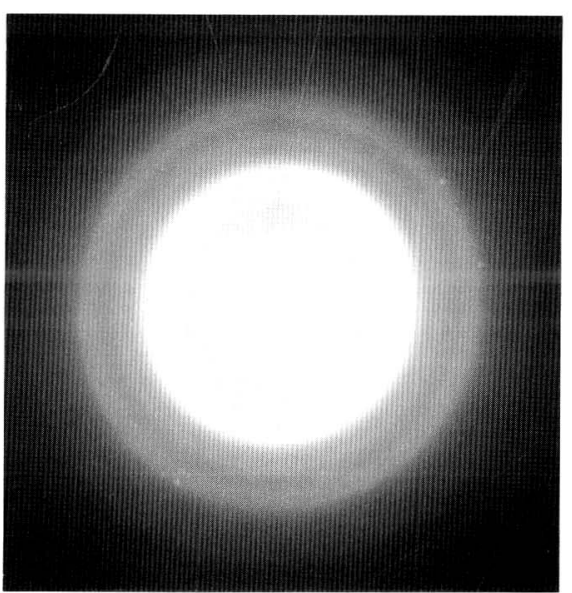

Fig. 11. Electron diffraction pattern of calcified deposits on day 7 after implantation. The diffraction pattern is the same as that of femora. 


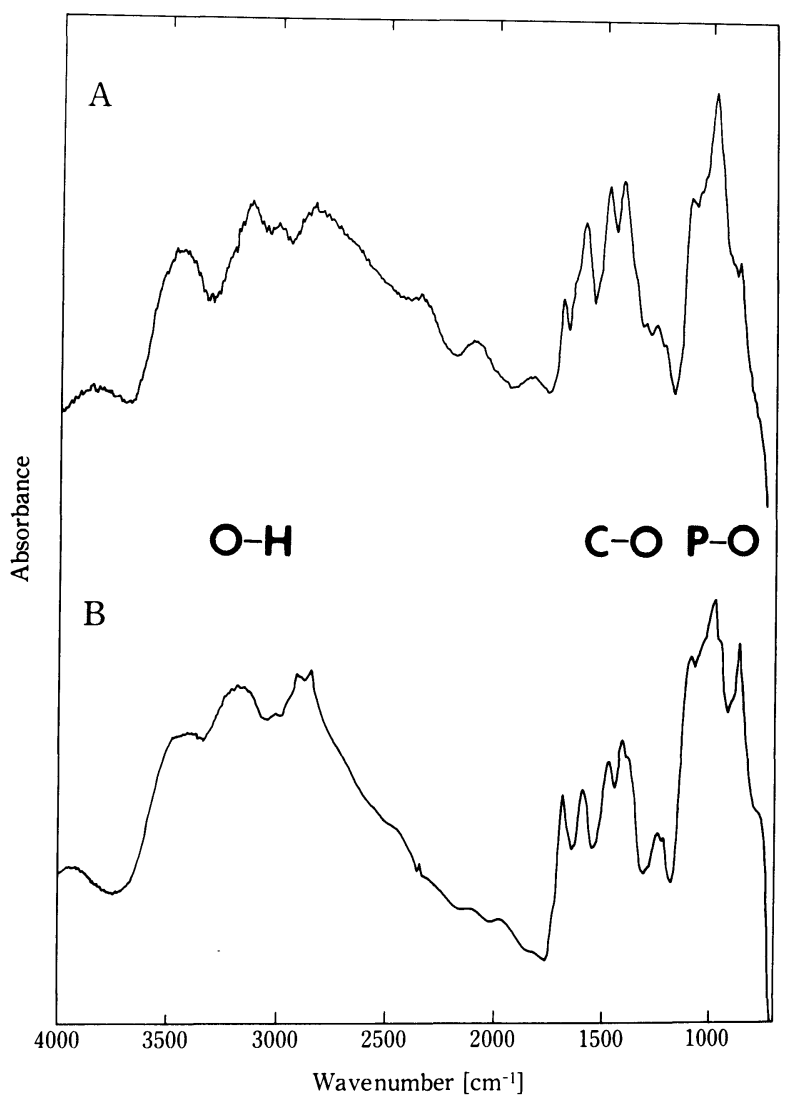

Fig. 12. FT-IR spectrum of calcification sites of BMG on days 7 (A) and 15 (B) after implantation, demonstrating peaks of phosphate groups (P-O), carbonate groups (C-O) and hydroxy groups $(\mathrm{O}-\mathrm{H})$. The peaks of phosphate groups $\left(870-1,100 \mathrm{~cm}^{-1}\right)$ are due to mixtures of hydroxyapatite (964 and $1,010 \mathrm{~cm}^{-1}$ ) and other calcium phosphates (981 and $1,060 \mathrm{~cm}^{-1}$ ). The peaks at 964 and $1,010 \mathrm{~cm}^{-1}$ are higher in $\mathbf{B}$ than in $\mathbf{A}$. The peak at $1,425 \mathrm{~cm}^{-1}$ also increases between day 7 and 15 .

REDDI and HugGins examined the change in calcium content of implants after subcutaneous implantation of demineralized bone powder, and stated that the increase in their calcium content from day 8 was chiefly due to calcification of cartilage (REDDI and HugGins, 1972). In the present study cartilage calcification was seldom seen in or among the sites of the BMG before day 7, but from day 10 cartilage calcification was seen. "Acellular mineral deposition" in the BMG was observed from day 5 in some specimens, and high calcium contents of the BMG specimens began from day 7. The "acellular mineral deposition" continued until at least day 15 after implantation when new bone formation by osteoblasts was observed near regions of the "acellular mineral deposition". The contents of both calcium and phosphate began to increase conspicuously from day 7 , and they converted to hydroxyapatite or carbonateapatite from day 7 to day 15 (Figs. 9, 12).

Calcifications of endochondral ossification observed by FT-IR microscopy (MENDELSOHN et al., 1989) and on the mineralization by collagenase-released matrix vesicles in vitro (SAUER and WUTHIER, 1988) are similar to the acellular mineral deposits composed of hydroxyapatite and carbonateapatite.

Our results indicate that the mechanism of "acellular mineral deposition" is different from that of bone formation, which involves osteoblasts, matrix vesicles and osteoclasts (ANDERSON, 1985). NIMNI et al. (1988) showed that the calcification observed after the implantation of cross-linked various collagens was different from new bone formation induced by the demineralized bone matrix.

The present study suggests that both calcium and phosphate might be supplied from blood vessels and they might be deposited on some debris of BMG by heterogenic nucleation. The concentration of minerals in the BMG matrix probably depends on the architecture of the BMG rather than on its biochemical conditions. We have already reported that the architecture of BMG influences new vascularization, calcification and bone induction (YAMASHITA et al., 1991a). After calcification, bone formation usually started with the appearance of osteoclasts and osteoblasts (RosEnBLum et al., 1976).

The specific accumulation of minerals in the BMG matrix probably depends on some architectural feature of the BMG, possibly denatured collagen fibrils. Further studies are required on the essential features prepared for specific accumulations of the components necessary for bone formation.

\section{REFERENCES}

Anderson, H. C.: Bone and mineral research 3. Elsevier Science Publishers, Amsterdam, 1985 (p. 109).

LiNDEN, G. J.: Bone induction in implants of decalcified bone and dentine. J. Anat. 119: 359-367 (1975).

Mendelsohn, R., A. Hassankhani, E. DiCarlo and A. BoSKEY : FT-IR microscopy of endochondral ossification at $20 \mu$ spatial resolution. Calcif. Tiss. Int. 44: 20-24 (1989).

Nimni, M. E., S. Bernick, D. T. Cheung, D. C. Ertl, S. K. Nishimoto, W. J. Paule, C. Salka and B. S. STRATES: Biochemical differences between dystrophic calcification of cross-linked collagen implants and mineralization during bone induction. Calcif. Tiss. Int. 42: 313-320 (1988). 
Plasmans, C. M. T., W. Kuypers and T. J. J. H. Slooff: The effect of ethane-1-hydroxy-1, 1-diphosphonic acid (EHDA) on matrix induced ectopic bone formation. Clin. Orthop. 132: 233-243 (1977).

REDdi, A. H. and C. HugGins: Biochemical sequences in the transformation of normal fibroblasts in adolescent rats. Proc. Nat. Acad. Sci. USA 69: 1601-1605 (1972).

Rosenblum, I. Y., R. S. McCuskey, N. C. McNeal, G. A. Kirckaert, L. Flora and C. A. Metzger: The effects of EHDP on regenerating trabecular bone using in vivo microscopic, light and electron microscopic and electron microprobe techniques. Calcif. Tiss. Res. 20: 91-104 (1976).

Sampath, T. K., N. Muthkumaran and A. H. Reddi: Isolation of osteogenin, an extracellular matrix-associated, bone inductive protein, by heparin affinity chromatography. Proc. Nat. Acad. Sci. USA 84: 71097113 (1987).

SAUER, G. R. and R. E. Wuthier: Fourier transform infrared characterization of mineral phase formed during induction of mineralization by collagenase-released matrix vesicles in vitro. J. Biol. Chem. 263: 13718-13724 (1988).

URIST, M. R.: Bone: Formation by autoinduction. Science 150: 893-899 (1965).

Urist, M. R., H. Iwata, P. L. Ceccotti, S. D. Boyd, R. M. MCDowell and C. ChiEN: Bone morphogenesis in implants of insoluble bone gelatin. Proc. Nat. Acad. Sci. USA 70: 3511-3515 (1973).

Urist, M. R., A. J. Mikulski, M. Nakagawa and $K$. YEN: A bone matrix calcification-initiator noncollagenous protein. Amer. J. Physiol. 232 (3): C115-127 (1977).

Urist, M. R., Y. K. Huo, A. G. Brownell, W. M. Hohl, J. Buyske, A. Lietze, P. Tempst, M. Hunkapiller and R. J. Delange: Purification of bovine bone morphogenetic protein by hydroxyapatite chromatography. Proc. Nat. Acad. Sci. USA 81: 371-375 (1984).
Wozney, J. M., V. Rosen, A. J. Celeste, L. M. Mitsock, M. J. Whitters, R. W. KRIZ, R. M. Hewick and E. A. WANG: Novel regulators of bone formation: Molecular clones and activities. Science 242: 1528-1534 (1988).

Yamashita, K., Y. Horisaka, Y. OKamoto, Y. Yoshimura, N. Matsumoto, J. Kawada and T. Takagi: Architecture of implanted bone matrix gelatin influences heterotopic calcification and new bone formation. Proc. Soc. Exp. Biol. Med. 197: 342-347 (1991a).

Yamashita, K., Y. Horisaka, Y. OKamoto, Y. Yoshimura, N. Matsumoto, J. Kawada and T. Takagi: Effect of bupivacaine on muscle tissues and new bone formation induced by demineralized bone matrix gelatin. Acta Anat. 141: 1-7 (1991b).

Yamashita, K., Y. Horisaka, K. Satomura and T. TAKAGI: Analysis of minerals on initial calcification induced by bone matrix gelatin. Jap. J. Oral Biol. 33: 166-173 (1991c).

Dr. Kikuji Yamashita

Department of Anatomy

University of Tokushima School of Dentistry

3-18-15 Kuramoto, Tokushima

770 Japan

山下菊治

770 徳島市蔵本町 3-18-15

徳島大学歯学部

解剖学講座 